\title{
Oversized and Underused: Size Matters in Academic Libraries 1
}

\author{
D. Yvonne Jones
}

Data on the collection size, shelving, and usage of oversize books in the general library collection was requested using an e-mail survey targeted at fifty U.S. liberal arts college libraries. Typical size of oversize collections ranged from a few hundred to almost 200,000 volumes, with a median collection size of 6,359 and median percentage oversize of 1.6 percent. When the percentage circulation within the oversize collection was compared with the percentage circulation within the general collection, statistically significantly lower circulation was evident for oversize volumes (one-sided $\mathrm{P}=0.02$ ), with a surprisingly small median difference of 3 percent.

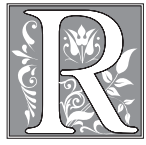

ecently, the liberal arts college library in which I work conducted a major shelving shift that involved possible relocation of the oversize collection. The optimal placement of the oversize collection was a subject for discussion. In an effort to benefit from the experience of other, similar libraries, the library science literature was consulted; however, the best shelving arrangement for oversize volumes is not a popular research topic. In fact, a search of the Library Literature \& Information Science bibliographic database (which indexes major periodicals in the field as well as selected books and proceedings starting from 1984$)^{1}$ resulted in only one article dealing with oversize books and shelving concerns. This 1996 article provides building plans for big book racks to be used in shelving the large reading instruction books encountered in school media centers. ${ }^{2}$ Unfortunately, building shelving was not our concern as much as the best placement of the existing shelving to optimize access.

After searching the research literature, the next logical path seemed to directly ask other libraries about their shelving practices for oversize books. Informal discussions among librarians often reveal the challenges of dealing with oversize material. There is a perception that the more closely the oversize material can be shelved to the rest of the volumes on the same subject, the more likely it will be accessed; however, there are no data to demonstrate this belief. This paper shares results from an e-mail survey conducted to obtain such data about shelving and use of oversize books and to make these data available to the larger library community.

\section{Methods}

An e-mail survey of the top fifty liberal arts colleges in 2005 listed by U.S. News and World Report was conducted during 
January through April of 2005. ${ }^{3}$ The survey was a short five-question open-ended query asking for information about how oversize books are handled at each of these top colleges' libraries. Specific questions asked whether the oversize collection circulated, the size of the collection, usage statistics in comparison with the rest of the circulating collection, and how oversize books are shelved at each institution. A final question invited general comments about the oversize collection. The survey is shown in appendix A.

\section{Response Rate}

The initial response rate from the e-mail survey was 58 percent (29 colleges responding from 50 surveyed). A follow-up e-mail request was sent to colleges who had not responded within eight weeks of receiving the survey and a further eight responses were received, yielding a final response rate of 74 percent (37 colleges). This response rate is considerably better than the 21 percent reported by Michael D. Kaplowitz, Timothy D. Hadlock, and Ralph Levine in 2004 for e-mail only sur-

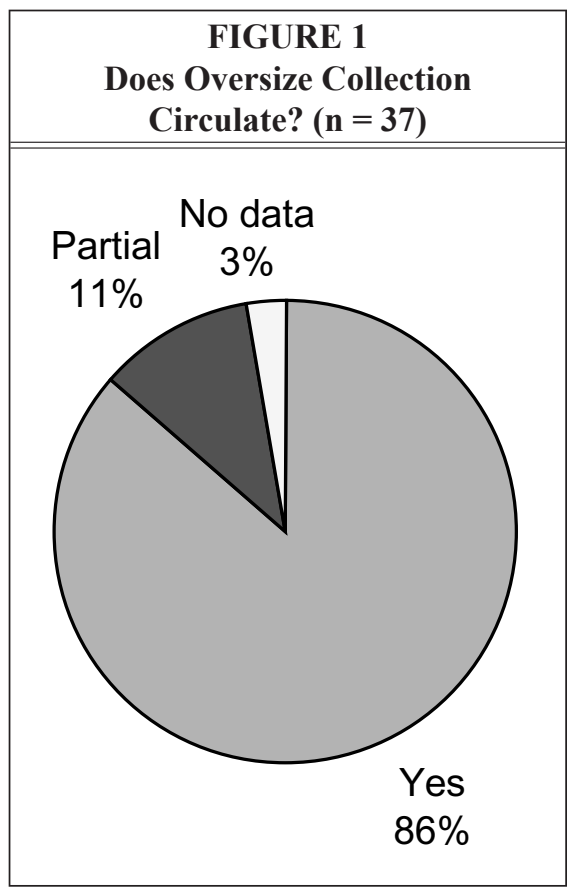

veys in comparison with mail, postcard, or combination surveys. ${ }^{4}$ The 74 percent library response rate obtained here also exceeds the highest rate reported in a 2001 review by Kim Sheehan of e-mail survey response rates. ${ }^{5}$ Sheehan's review article notes a pattern of decreasing response rates over time from a high of 72 percent in 1992 to more recent responses of 28 and 24 percent, consistent with the 21 percent rate reported by Kaplowitz et al. previously mentioned.

Many factors could contribute to the higher response rate obtained in this survey of academic libraries. It is clearly a very defined population, with Internet proficiency expected in the professional staff. The libraries targeted in this survey are also from top-rated liberal arts colleges where one would expect an elevated level of service that extends to outside requests for assistance.

\section{Oversize Collection Description}

In response to the primary question of whether the library has a circulating oversize collection, figure 1 shows that the majority of libraries did have a circulating collection (32 libraries, $86 \%$ of the sample). Three libraries noted that some oversize books circulated and others did not and that the group that was differentiated was typically the art books. Either "only art books circulate" or "art does not circulate" were the added comments. One college responded that its oversize collection did not circulate; however, it also explained it has a policy of not designating any book as oversize except art folios, which did not circulate. Given that policy, this library could reasonably be grouped with the previous three with "mixed" circulation, bringing to 11 percent the number of surveyed libraries with partial circulation of their oversize collection. One library did not answer this question. As figure 1 demonstrates, in this group of highly rated liberal arts college libraries, the overwhelming majority intend for their oversize material to circulate. 
An unexpected finding of this survey was that the designation of "oversize" was not as universally used as presumed. In reviewing survey responses, it became clear that a sizable number of libraries use other terminology. Figure 2 provides a graphical depiction of the various descriptor terms utilized. The majority of libraries (24 libraries, 65\%) use the term oversize (sometimes further differentiated into super oversize, double oversize, and regular oversize); eleven libraries (30\%) use the term folios and quartos; one library uses the designations " $\mathrm{X}$ " and " $\mathrm{XX}$ ", and one library did not provide data.

\section{Size of Oversize Collection}

Differences in the descriptor used led directly to exploration of the question of what determines the size cutoff for "oversize" in these colleges? The question of what size constitutes "oversize" varied from library to library, although within fairly narrow ranges. Although this information was not asked directly, several libraries offered their cutoff information and a few responded to this question when asked the "size" of their oversize collection. Specific cutoffs listed

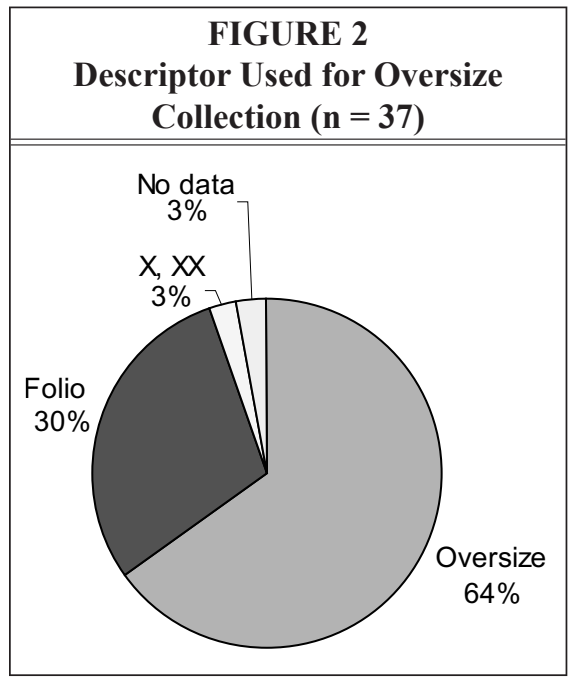

were $>=27.5,28,30,32,33,35$, and $38 \mathrm{~cm}$. Several libraries emphasized their use of separate oversize cutoffs for art (N), photography (TR), or music (M) materials. As so many books in these classifications are larger in size, higher cutoffs tend to be used to designate an oversize volume in these areas.

Survey questions asking for quantitative data about the oversize and general collections were not answered by all 37

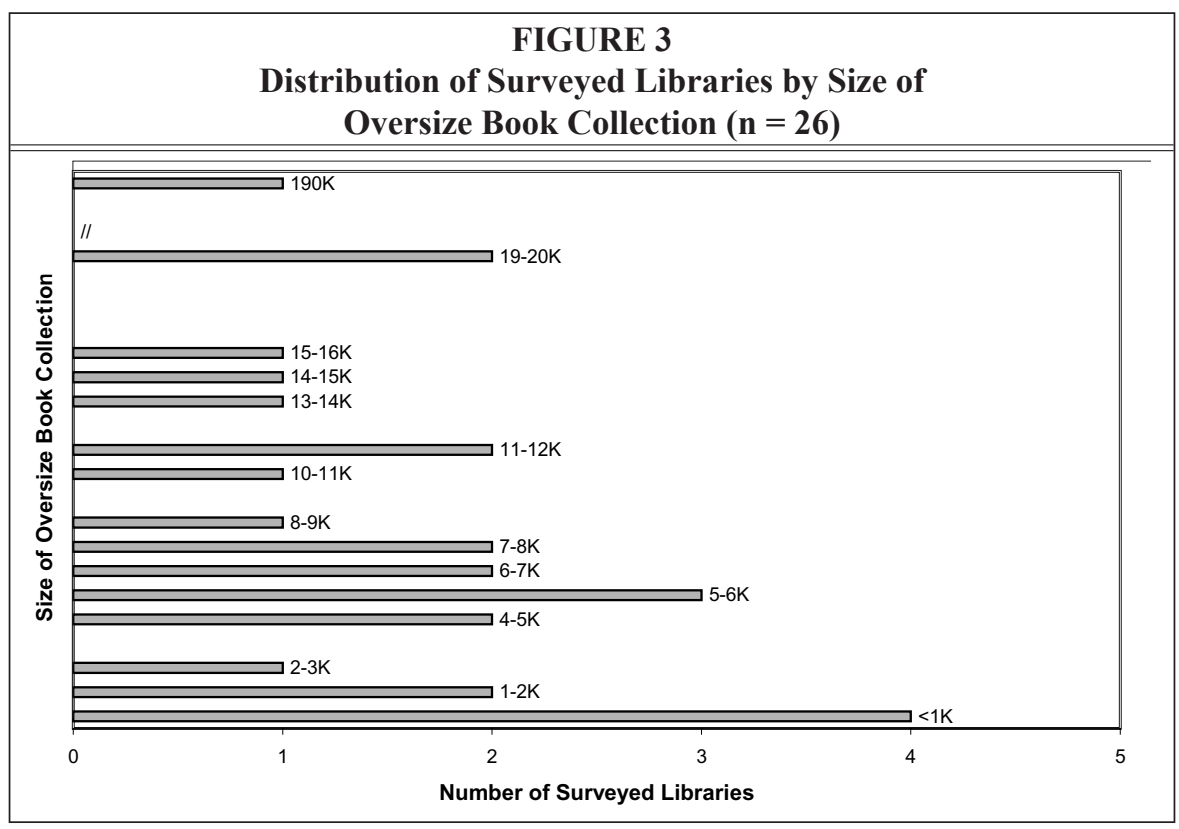


colleges. Only 26 of the 37 responding libraries $(70 \%)$ provided data on the number of oversize volumes in comparison with the general circulating collection. (See figure 3.) The size of the oversize collections reported ranged markedly in this group of select college libraries, from a few hundred to $180,000-200,000$ volumes. The upper level reported (180,000-200,000 volumes or $190 \mathrm{~K}$ as an average estimate) is a clear outlier, reported by the college with the largest overall collection (one million volumes) and a particularly large art collection. For this college library, the oversize collection represented 15 to 17 percent of the total collection. After excluding this library, the oversize collections still varied 100 -fold, from 200 to 20,000 $($ mean $=7,364 ;$ median $=6,359 ; \mathrm{n}=$ $25)$. In contrast, the total circulating collection in the libraries surveyed varied only fivefold, from 180,000 to 932,898 total volumes $($ mean $=440,949 ;$ median $=$ 400,000; $\mathrm{n}=25$ ).

Examining the oversize collection as a percentage of the total circulating collections, figure 4 shows the majority of libraries with 2 percent or less of their collections designated as oversize. Twenty-one of the 26 libraries providing data $(81 \%)$ reported $\leq 2$ percent as oversize. Only five libraries reported higher percentages of $3,4,4,6$, and 16 percent from the library previously noted with the extensive art collection. When the library reporting the extremely high 16 percent value was included, the mean oversize percentage was 2.2 percent and the median value was 1.6 percent. Excluding this library resulted in a mean oversize percentage of 1.7 percent and the same median value of 1.6 percent.

\section{Shelving the Oversize Collection}

In describing where their oversize collections were shelved, the responding libraries reported several basic strategies. (See figure 5.) The most common strategies were shelving the collection in a completely separate area (17 libraries, $47 \%$ ) and shelving oversize in a separate area, but on the same floor with the cor-

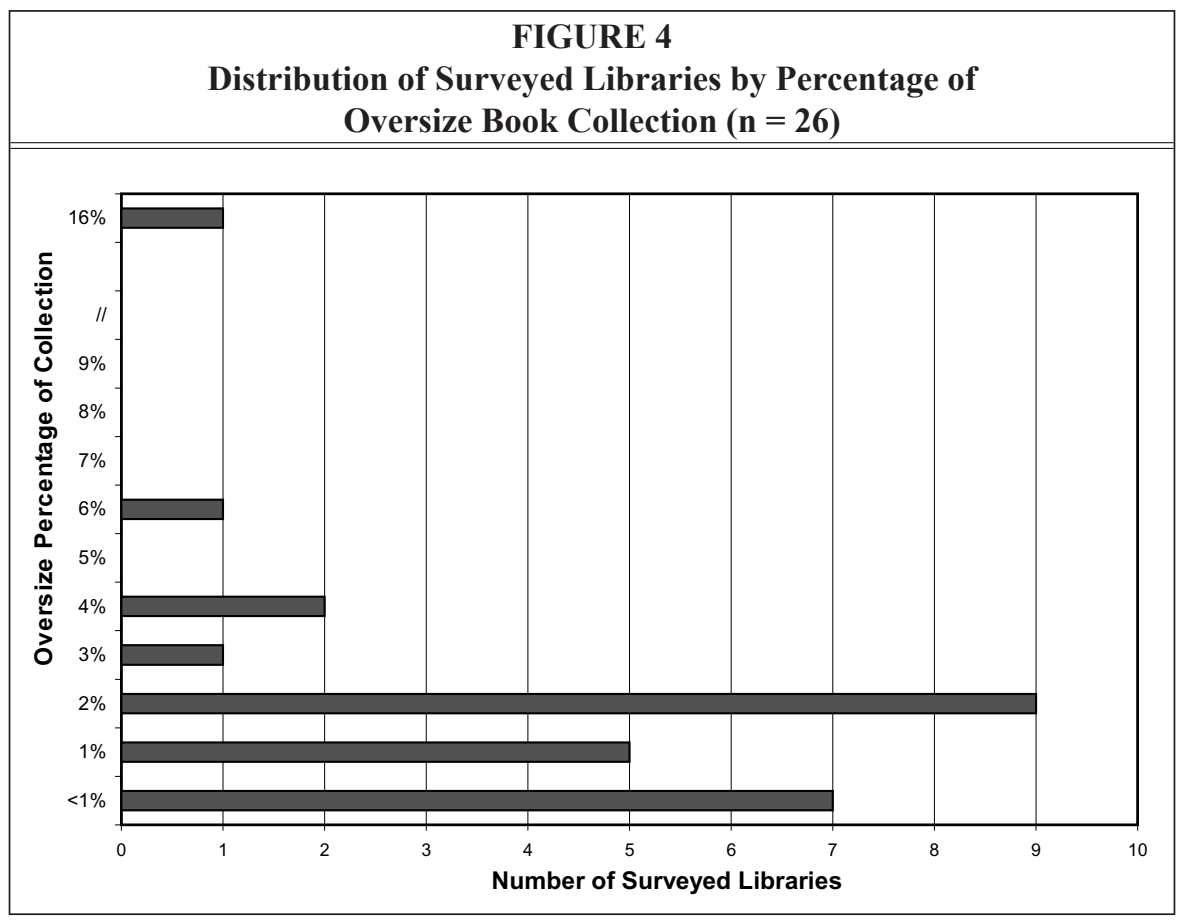


responding classification in the general collection (10 libraries, $28 \%$ ). Seven libraries (19\%) reported a mixture of strategies, with part of the oversize collection shelved separately and other parts, usually the art collection, interfiled or placed adjacent to the general circulating books in that classification. Two libraries $(6 \%)$ reported alternative strategies, one shelving the oversize at the start of each major call number breakdown and the other using the bottom shelves of each Library of Congress designation. One library did not provide data.

Several libraries commented in replying to the survey about the unique problems of oversize books and compact shelving. It is definitely worth warning others that in planning for shelving shifts, there are special concerns for oversize volumes. The support cross-braces found in some shelving limit the depth to which oversize books can be shelved and must be considered. In addition, with compact shelving, the distance allowed between shelves in the closed position may have to be adjusted to accommodate the overhang of oversize volumes on the shelf. Compact shelving concerns magnify the usual extra considerations of dealing with shelving oversize books.

\section{Circulation of Oversize Books}

In examining the key question of whether circulation usage of oversize books is the same as the general collection circulation, once again, the sample size of libraries with complete data decreased. Only sixteen of the surveyed libraries provided sufficient quantitative data to allow statistical analysis of circulation. Oversize circulation was examined initially by comparing the percentage of the collection designated as oversize with the percentage of the annual circulation that came from oversize books. Theoretically, a selected collection such as oversize would

be represented in the circulation statistics proportionally to its size in the overall collection. Figure 6 shows the difference between the percentage of oversize in the collection minus the percentage in the circulation statistics for the sixteen libraries surveyed with complete data.

The first data point, with a difference of 2.4 percent more circulation of oversize materials than proportion in the overall collection, stands out as the largest single difference noted. The respondent from this library commented on this finding as a surprising result of answering the survey. Despite the fact that the oversize collection is shelved in a separate room from the rest of the circulating collection, this library showed markedly higher proportional circulation from the oversize collection. The library respondent suggested that this result was an example of the success of the reference librarians in directing readers to the desired area. Certainly other assisting staff as well as signage may contribute to this result, as well as a desirable oversize collection; however, it is clear that this library is an example where the expected outcome of lesser oversize circulation is not evident.

Of the sixteen libraries with quantitative data, only five showed the result of higher circulation in the oversize collection than 
their proportional contribution. Eleven libraries displayed results in the expected direction, with a lower circulation percentage than their proportion in the collection. It should be noted that because oversize collections contribute only a small proportion to the overall collection, there is not a wide range of variation for differences to manifest themselves. In figure 6, the entire range covers only about 4 percent. No statistically significant differences were evident in examining the paired $t$ test for these data, although if the single unusual result discussed above $(2.4 \%$ higher oversize circulation) is excluded, there is a significantly lower circulation noted (one-sided $\mathrm{P}=0.02$ ).

Another way to examine the circulation usage of the oversize collection is to compare the percentage of the oversize collection that circulates with the percentage of the overall general collection circulating. The expectation would be that circulation within the oversize collection would be a smaller percentage than the circulation within the general collection.
Figure 7 shows the distribution of the difference between the percentage of the general collection circulating minus the percentage of the oversize collection circulating.

Examining the circulation differences in this way provides a greater than sixfold higher range over which differences can be examined. There are still five libraries showing greater percentage circulation in the oversize collection than in the general collection, versus eleven libraries in the expected direction. However, with a greater range over which to examine differences, there is no single outstanding exception. Statistically testing these differences yielded a significantly lower circulation within the oversize collection (one-sided $\mathrm{P}=0.02$ ). Although this is the expected result, what is surprising in these data is the relatively low amount of difference found. The mean difference observed was 3.26 percent and the median difference was only 3.05 percent. Despite the fact that almost all the respondents to the e-mail

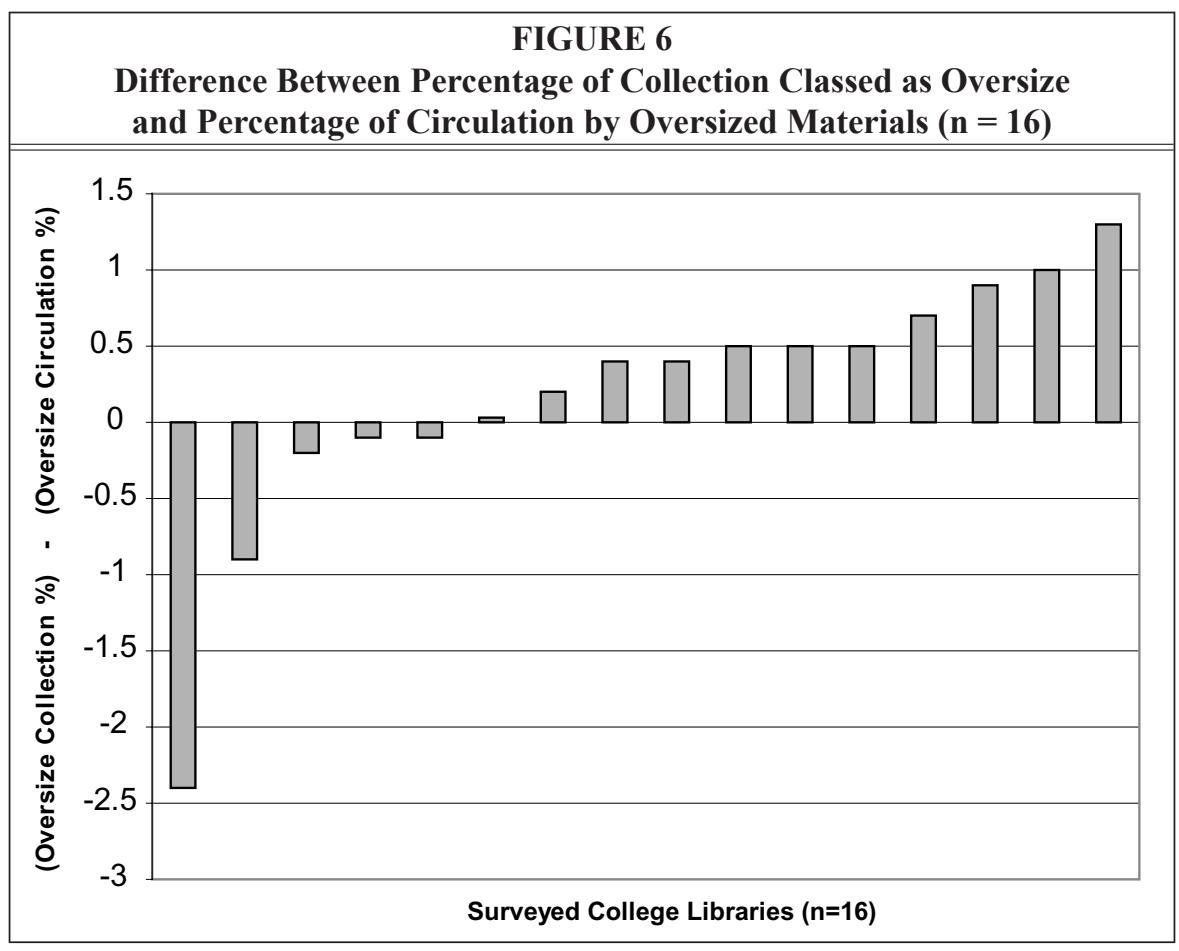




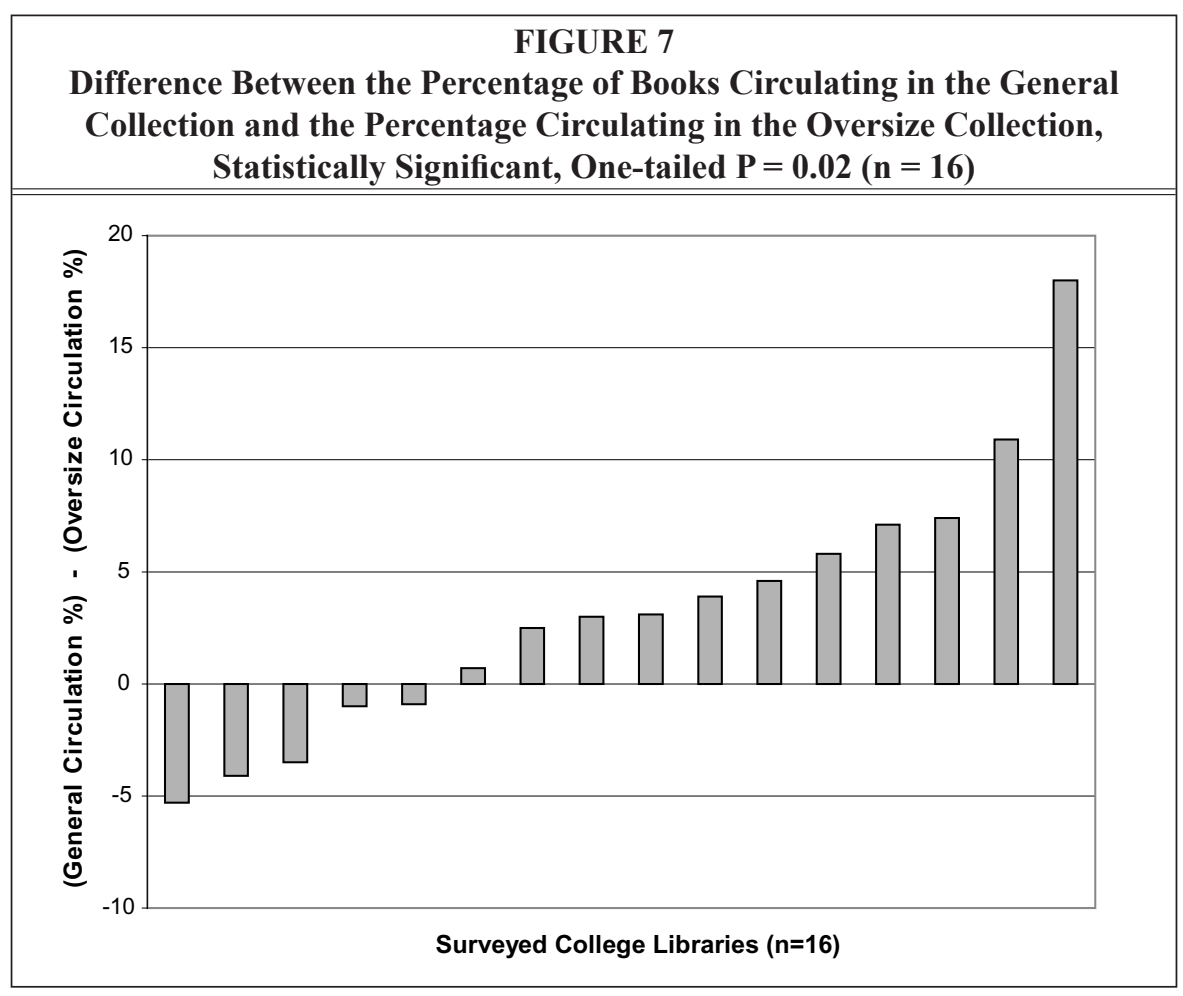

oversize query mentioned at some point that they expected that their collection was being underutilized, the data show that although most collections are indeed used less, it is not by a large amount. A few libraries found, sometimes to their own surprise, that they proportionally utilize their oversize collection more than the general collection.

A closer examination of each of the sixteen surveyed libraries and their shelving strategies showed no correlation between the shelving strategy and the circulation usage. The most-used oversize collection was shelved in a separate room. In fact, four of the five libraries with greater proportional use of the oversize collection shelved the oversize collection in a separate room. For the eleven libraries with decreased circulation in the oversize collection, shelving was in a separate room for five libraries and in a separate area on the same floor as the general classification for six libraries.

\section{Conclusion}

The responses received from this e-mail survey demonstrate that oversize books continue to provide particular challenges for the personnel determining their optimal location for best usage. Oversize collections tend to be a small percentage of the total collection, typically $\leq 2$ percent. By definition, their size creates particular difficulties in arrangement on the shelving used for most of the collection. Most libraries shelved their oversize material in a completely separate area $(47 \%)$; the next most common shelving strategy was to place the oversize material in a separate area of the same floor where the general circulating material with the same classification is found (28\%). Examining the data on circulation of the oversize collection showed no apparent difference in circulation based on the shelving strategy used.

Circulation of oversize books was significantly lower when the percentage 
circulation within the oversize collection was compared with circulation within the general collection. However, several libraries demonstrated the exact opposite: higher proportional circulation within the oversize collection. The general result of lower circulation with oversize books is the expected wisdom, but it is interesting to note that the degree of reduction is quite small (median difference of $3 \%$ in circulation). Although it can only be speculative, as there are no historical data on this topic, the smaller than expected difference in circulation may be a result of the change in browsing and retrieving behavior of library patrons. Previously, when browsing for material physically "in the stacks" was a more prominent behavior, placement of oversize material in a separate area might lead to their exclusion. The current practice of browsing for material through online catalogs should make the location of the oversize collection not as important a factor.

\section{Appendix A}

\section{Oversize Books E-mail Survey \\ Oversize Books Query (Subject line)}

I write to request your help with an inquiry concerning oversize books. We are currently making shelving decisions for a move at our library and are trying to obtain information about the best placement of the oversize collection. It would be helpful for us if we could determine from other libraries the following information:

\section{Do you have a circulating oversize collection?}

2. If so, how does it compare in size with your general circulating collection? (Could you please provide number of volumes for both the oversize and general collection?)

3. Where do you shelve your oversize collection? (Is it in a completely separate area from the general circulating collection, or at the bottom of the shelf for each LC designation, or some other scheme?)

4. How does your oversize collection compare with the general circulating collection in usage? (Could you please provide the number of charges (checked out of the library) for the oversize collection and the general circulating collection during the past year?)

5. Is there anything else regarding the oversize collection that you would like to share with us, caution us about, encourage us to do, whatever?

Thank you so much for your help with these questions.

Sincerely,

D. Yvonne Jones

Olin Library

Rollins College 


\section{Notes}

1. Library Literature \& Information Science Full Text. Available online from http://www.hwwilson.com/databases/liblit.htm. [Accessed 1 June 2005].

2. Randall M. MacDonald, "Oh! Those Oversize Books: A Solution for Storage and Inventory," School Librarian's Workshop 16 (Apr. 1996): 9.

3. U.S. News \& World Report. America's Best Colleges 2005. Liberal Arts Colleges: Top Schools. Available online from http://www.usnews.com/usnews/edu/ college/ rankings/brief/libartco/tier1/ libartco_brief.php. [Accessed 18 January 2005].

4. Michael D. Kaplowitz, Timothy D. Hadlock, and Ralph Levine, "A Comparison of Web and Mail Survey Response Rates," Public Opinion Quarterly 68, no.1 (2004): 94-101.

5. Kim Sheehan, "E-mail Survey Response Rates: A Review," Journal of Computer-mediated Communication 6, no. 2 (Jan. 2001). Available online from www.ascusc.org/jcmc/vol6/issue2/sheehan. html. [Accessed 31 March 2005]. 